\title{
Mídia audiovisual no interior do Brasil e produção local de informação
}

\author{
Audiovisual media in the countryside of Brazil and the production of local information \\ Medios audiovisuales en el interior de Brasil y la producción local de información
}

DOI: https://doi.org/10.1590/1809-5844202126

\section{Sonia Virgínia Moreira ${ }^{1}$}

https://orcid.org/0000-0001-9583-4400

\section{Nélia Rodrigues Del Bianco ${ }^{2}$}

http://orcid.org/0000-0002-3701-0929

\section{Cézar Franco dos Santos Martins ${ }^{3}$}

https://orcid.org/0000-0003-2292-4418

${ }^{1}$ (Universidade do Estado do Rio de Janeiro, Faculdade de Comunicação Social, Programa de Pós-Graduação em Comunicação. Rio de Janeiro - RJ, Brasil).

${ }^{2}$ (Universidade de Brasília, Faculdade de Comunicação, Programa de Pós-Graduação em Comunicação. Brasília - DF, Brasil).

${ }_{3}^{3}$ (Universidade Federal de Juiz de Fora, Faculdade de Comunicação, Programa de Pós-Graduação em Comunicação. Juiz de Fora - MG, Brasil).

\section{Resumo}

Este artigo se propõe a verificar a existência ou inexistência de produção local de conteúdo informativo em emissoras de rádio e em retransmissoras de rádio e TV no universo dos 32 municípios brasileiros de IDHM Muito Baixo localizados nas regiões Norte e Nordeste. A abordagem desses municípios emprega conceitos de mídia local e de jornalismo de proximidade para fundamentar a análise dos meios nas localidades. Os arranjos territoriais de mídia e de produção de informação em emissoras e retransmissoras locais são os objetos pesquisados. A consulta a textos legais e a observação empírica do conteúdo (re)produzido por emissoras de rádio nos municípios estudados sugerem que há um direcionamento, natural ou intencional, na implantação de sistemas de reprodução da informação originada de cidades médias ou centros urbanos. Os conceitos usados são: territórios, mídia local e “desertos de notícias".

Palavras-chave: conteúdo local. emissoras de rádio. retransmissoras RTV. “desertos de notícias”. 


\begin{abstract}
The purpose of this article is to verify whether there is or there is not local news content being produced by radiobroadcasters and by radio and TV re-broadcasters in the 32 municipalities with very low development indicators (Very Low IDHM), all of them in the North and in the Northeast regions. The scope of the study was determined by the lack of information either on media practices or local characteristics, which entailed the use of local media and local journalism concepts to advance the field analysis. The article considers territorial arrangements and media arrangements in observing the production of radio and RTV re-broadcasters. Legal and policies documents and empirical observation suggest that there is a direction (natural or intentional) in establishing a system of reproduction of information from other media in larger cities. The concepts used are territories, local media, and "news desert".
\end{abstract}

Keywords: local content. radiobroadcast stations. radio and tv re-broadcasters. "news deserts".

\title{
Resumen
}

El objetivo de este artículo es verificar la existencia o no de producción local de contenidos informativos en las emisoras de radio y retransmisoras de radio y televisión en 32 municipios en Brasil con indicadores muy bajo (IDHM Muito Baixo) ubicados en las regiones Norte y Nordeste. El enfoque de estos municipios impone el uso de conceptos que apoyan los argumentos del análisis de datos de los medios de comunicación relacionados con estas localidades. El estudio observa los arreglos territoriales de medios y de producción de información en el ámbito de las emisoras de radio y retransmisoras de radio y TV. La consulta de los textos legales y la observación empírica de los contenidos producidos por las emisoras de radio en las ciudades estudiadas sugieren que existe una dirección (natural o intencional) de un sistema para la reproducción de la información de las ciudades medianas o grandes. Los conceptos utilizados son: territorios, noticia local y "desierto de noticias".

Palabras clave: contenido local. emisoras de radio. retransmisoras de radio y TV. "desierto de noticias".

\section{O objeto e o objetivo}

A proposta deste artigo é verificar a existência ou inexistência de serviços de mídia e de produção local de conteúdo informativo em emissoras de rádio e em retransmissoras de TV nos 32 municípios brasileiros com Índice de Desenvolvimento Humano Municipal (IDHM) Muito Baixo, aqueles com os piores indicadores sociais no Brasil, localizados nas regiões Norte e Nordeste. Consideramos essa faixa de índice de desenvolvimento (os indicadores do IDHM se distribuem em muito baixo, baixo, médio, alto, muito alto) como território geopolítico pertinente e precisando de análise, no qual cabe a observação da organização local de mídia e de produção de conteúdo local nos 32 municípios distribuídos em nove estados (Quadro 1). 
Quadro 1 - Municípios com IDHM Muito Baixo, por estado

\begin{tabular}{ll|ll}
\hline Estado & Município & Estado & Município \\
\hline Acre & Jordão & Pará & $\begin{array}{l}\text { Anajás } \\
\text { Afuá } \\
\text { Bagre } \\
\end{array}$ \\
& & & $\begin{array}{l}\text { Cachoeira do Piriá Chaves } \\
\text { Ipixuna do Pará } \\
\text { Melgaço }\end{array}$ \\
& & & Portel \\
\hline Alagoas & Inhapi & & Manari \\
& Olivença & Pernambuco & Assunção do Piaú́ \\
\hline Amazonas & Atalaia do Norte Itamarati & Piauí & Betânia do Piauí \\
& Ipixuna & & Caxingó \\
& Maraã & & Cocal \\
& Pauini & & São Francisco de Assis do Piauí \\
\hline Santa Isabel do Rio Negro & & Amajari \\
& Santo Antônio do Içá & & Uiramutã \\
\hline Bahia & Itapicuru & Roraima & \\
& & & \\
\hline Maranhão & Fernando Falcão & & \\
& Jenipapo dos Vieiras & & \\
& Marajá do Sena & & \\
& Satubinha & & \\
\hline
\end{tabular}

Fonte: PNUD. Atlas do Desenvolvimento Humano no Brasil, 2010.

$\mathrm{O}$ artigo se insere em um projeto mais amplo, que estuda a infraestrutura existente de mídia e telecomunicações no território brasileiro, a começar pelos pequenos municípios. Aqui, considera especificamente aqueles com Índice de Desenvolvimento Humano Municipal Muito Baixo (menor que 0.5 em uma escala na qual 1 representa o maior grau) segundo indicadores do Atlas do Desenvolvimento Humano no Brasil. O Atlas é uma parceria entre o PNUD Brasil - Programa das Nações Unidas para o Desenvolvimento, a Fundação João Pinheiro, de Minas Gerais, e o Instituto de Pesquisa Econômica Aplicada - IPEA. “Traz o Índice de Desenvolvimento Humano Municipal (IDHM) e outros 200 indicadores de demografia, educação, renda, trabalho, habitação e vulnerabilidade para os municípios brasileiros" (ATLAS BRASIL, 2010a).

Ao longo do tempo e de modo simultâneo, os indicadores de desenvolvimento apontados no IDHM se refletem nos meios de comunicação locais e regionais. O predomínio do audiovisual - emissoras de rádio e televisão, acrescidas em 2005 das retransmissoras de rádio e TV com a aprovação do Regulamento do Serviço de Retransmissão de Televisão e do 
Serviço de Repetição de Televisão, ancilares ao Serviço de Radiodifusão de Sons e Imagens (BRASIL, 2005) - resultou das políticas de Estado para a comunicação, em especial as normas para a concessão de canais no setor da radiodifusão.

A democratização da comunicação, que é a defesa da aplicação no país dos princípios fundamentais do Direito à Comunicação (acesso à informação, viabilidade de produção de conteúdo, garantia de difusão e de distribuição), está em debate desde 1991 quando foi criada a Frente Nacional pela Democratização da Comunicação (FNDC), organizado por entidades de classe em seguida à Constituição de 1988 para acompanhar no Legislativo a promulgação das leis para a comunicação previstas no texto constitucional (FNDC, 2019), sugerir ajustes e colaborar para o avanço legal.

30 anos depois, a indústria de mídia segue predominantemente comercial, altamente concentrada, com a produção centralizada nas regiões Sudeste e Sul, que recebem 25,3\% dos investimentos em publicidade, direcionados principalmente à televisão aberta $(54,1 \%)$ (CENP, 2020). Quatro organizações e suas redes (Globo, Band, SBT e Record) alcançam pouco mais de $70 \%$ da audiência no país. Nos impressos diários, o grau de concentração reduz a pluralidade de fontes: mais de $50 \%$ dos leitores ainda se distribuem entre quatro grupos dos estados do Rio de Janeiro, São Paulo e Rio Grande do Sul: Grupo Globo, Grupo Folha, Grupo Estado e Grupo RBS (MOM BRASIL, 2018). O índice de concentração também é elevado entre os portais de notícias, com predomínio de quatro grupos - Globo/ G1, Folha/UOL, Record/R7 e Grupo Ongoing/iG - em 58\% da audiência on-line (MEIOS NO BRASIL, 2018). Acrescenta-se a esse quadro o aumento progressivo da participação de grupos religiosos proprietários de meios $^{1}$, que controlam algumas das 50 maiores redes brasileiras de rádio e TV, como mostra a pesquisa Monitor de Propriedade de Mídia - MOM (da sigla em inglês Media Ownership Monitor) ${ }^{2}$.

Hoje, o ambiente produzido pela cultura de mídia comercial e pela inexistência de uma política permanente de Estado para meios públicos não favorece a produção independente de mídia, sustentada por fontes variadas, sem depender de verbas públicas, econômicas ou religiosas $^{3}$. Consideremos, por exemplo, que o volume de investimento em publicidade na mídia comercial somou R\$ 8,9 bilhões entre janeiro e setembro de 2020 (CENP, 2020), enquanto o orçamento da principal (e única) empresa pública de comunicação foi estimado em R\$ 652 milhões de reais em 2020 (BRASIL, 2021). Além da publicidade, os interesses econômicos, políticos e religiosos têm capacidade de agendamento nos grupos de mídia e potencial para influenciar a opinião pública (MOM BRASIL, 2018).

1 Pelo menos seis grupos religiosos atuam em escala regional/nacional no Brasil: Grupo Record, Rede Gospel de Televisão, Rede Novo Tempo - Rádio e TV, Rede Católica de Rádio (RCR), Rede Vida TV, Rede Evangelizar de Comunicação.

2 Coordenado pela ONG Repórteres Sem Fronteiras (RSF), o projeto mapeou a mídia em 14 países até 2018. No Brasil, foram 50 veículos e redes de comunicação de rádio, TV, meios impressos e on-line.

3 Pelo menos seis grupos religiosos atuam em escala regional/nacional no Brasil: Grupo Record, Rede Gospel de Televisão, Rede Novo Tempo - Rádio e TV, Rede Católica de Rádio (RCR), Rede Vida TV, Rede Evangelizar de Comunicação. 
A cultura da mídia comercial influi, inclusive, na disposição das informações em bancos de dados públicos em versões consolidadas nacional ou regional. Há informações de recorte local, mas em estado bruto, dependendo de coleta, parametrizações e tratamento analítico. No Portal de Dados Abertos da Agência Nacional de Telecomunicações (ANATEL, 2020), os "quantitativos de acessos" de empresas autorizadas, concessionárias e prestadoras de serviço estão dispersos em arquivos anuais dispostos mês a mês, organizados em tabelas e em séries temporais identificadas por diversas entradas - empresas, grupos, tecnologias, municípios etc.

É quase um paradoxo: a liberdade de uso dos dados demanda um esforço enorme para superar, organizar e lapidar a informação. Informação que, por sinal, existe em relatórios pagos de empresas de auditoria e de análise de mercado (DELOITTE, 2020, KPMG, 2020), que reúnem dados atualizados dos diversos setores. A PWC é das poucas firmas de auditoria a abrir os resultados das pesquisas por segmentos, como a Pesquisa Global de Entretenimento, que apresenta macrotendências, consumo de livros, meios, dados, games, realidade virtual etc. (PWC BRASIL, 2021).

Todo o conjunto mostra a lógica dos grupos midiáticos no país, modelos comerciais que se estabeleceram nas metrópoles, com sucursais ou escritórios nos lugares menores ou com menos recursos para investimento publicitário. Deslocamentos desses grupos são mais administrativos e menos de produção e geralmente ocorrem em cidades médias ou capitais regionais, determinados pelo alcance do conteúdo nas regiões e nas localidades. O relatório Região de Influência das Cidades - REGIC 2018 indica, por exemplo, que em relação à difusão das informações, "a análise das redes de televisão aberta permite identificar, ao menos, parte da centralidade das Cidades em relação às telecomunicações e aos fluxos informacionais emitidos e recebidos nos centros urbanos” (IBGE, 2020). O rádio é meio de comunicação reconhecidamente local, sob a influência diversa e cíclica de governos, políticos, empresários e, a partir da década de 1980, também de religiosos.

De modo geral, não conhecemos os perfis demográficos e de audiência das cidades pequenas e sabemos pouco sobre a estrutura existente para a produção de mídia nesses locais, geralmente distantes ou de acesso difícil. Esta análise está fundamentada nos 32 municípios de IDHM Muito Baixo e se propõe a observar manifestações de mídia audiovisual, emissoras de rádio e retransmissoras de rádio e TV na escala social-midiática local.

\section{Território, mídia local, “desertos de notícias”}

A abordagem da mídia existente nos 32 municípios com Índice Muito Baixo de Desenvolvimento Humano (ATLAS BRASIL, 2010b) demanda a identificação de conceitos que sustentem os argumentos da análise dos dados mostrados pelas localidades.

Como interessa aqui verificar os arranjos territoriais de mídia e de informação no âmbito audiovisual, emissoras de rádio e retransmissoras de rádio e de televisão, a metodologia inclui, além do uso dos indicadores IDHM na seleção dos municípios, consultas 
a textos legais, entre os quais a regionalização da produção no Art. 221 da Constituição (BRASIL, 2019) $^{4}$ e a atualização de 2020 do Regulamento dos Serviços de Radiodifusão (BRASIL, 2020) ${ }^{5}$, que se somam à observação empírica do conteúdo distribuído por emissoras de rádio nos 32 municípios. Pretendemos examinar se há produção local e/ou qualquer direcionamento (natural ou intencional) nos 32 municípios que influencie a circulação de informação produzida em outras cidades. Os conceitos de território, mídia local e “desertos de notícias” compõem a base teórica do artigo.

O referencial para território vem do campo da Geografia. Como medida de lugar considera, como em Santos (2007, p. 14), que

O território não é apenas o conjunto dos sistemas naturais e de sistemas de coisas superpostas; o território tem que ser entendido como o território usado, não o território em si. O território usado é o chão mais a identidade. A identidade é o sentimento de pertencer àquilo que nos pertence. O território é o fundamento do trabalho; o lugar da residência, das trocas materiais e espirituais e do exercício da vida.

Também compartilha o entendimento da "geografia complexa” proposta por Haesbaert (2009), que mostra um mundo em rede no qual "a multiplicidade de escala gera múltiplos territórios”.

Dessa interação constante entre múltiplas escalas e territórios, surge e avança cada vez mais o uso do termo rede, que contribui para compreendermos essas articulações entre diferentes territorialidades bem como suas estruturações internas. (...) Identificar as redes de dimensão planetária e que, segundo alguns autores, servem de embrião para a formação de um 'território-mundo' é tão importante quanto identificar as redes de caráter local e regional que, muitas vezes, possuem potencial para propor organizações territoriais alternativas (HAESBAERT, 2009, p. 121-123).

O artigo se vale ainda da avaliação de Beltrão Sposito (2006), que considera o território como o espaço das diferenças entre o tempo da natureza e entre os eventos sociais

4 Constituição da República Federativa do Brasil, Art. 221- A produção e a programação das emissoras de rádio e televisão atenderão aos seguintes princípios: I - preferência a finalidades educativas, artísticas, culturais e informativas; II - promoção da cultura nacional e regional e estímulo à produção independente que objetive sua divulgação; III - regionalização da produção cultural, artística e jornalística, conforme percentuais estabelecidos em lei.

5 Por meio do Decreto 10.405, de 25 de junho de 2020, que alterou “o Regulamento dos Serviços de Radiodifusão, aprovado pelo Decreto no 52.795, de 31 de outubro de 1963, o Regulamento do Serviço de Retransmissão de Televisão e do Serviço de Repetição de Televisão, aprovado pelo Decreto no 5.371, de 17 de fevereiro de 2005, o Decreto no 5.820, de 29 junho de 2006, o Decreto no 8.139, de 7 de novembro de 2013, e o Regulamento do Serviço de Retransmissão de Rádio na Amazônia Legal, aprovado pelo Decreto no 9.942, de 25 julho de 2019, para dispor sobre a execução dos serviços de radiodifusão e o processo de licenciamento de estações de radiodifusão. 
e naturais porque "na escala geográfica não se avalia o resultado entre diferentes recortes territoriais, mas a forma como o tempo incide sobre diferentes territórios”:

(...) sabemos que se ampliam os níveis de determinação do global sobre o nacional, o regional e o local e por isso é cada vez mais significativo conhecer como essas múltiplas determinações incidem em cada contexto geográfico e histórico, não importando aqui a escala que tenhamos tomado como ponto de partida (área e período de estudo) (BELTRÃO SPOSITO, 2006, p. 153).

Na análise da mídia e do jornalismo locais, usamos como referência conceitos de proximidade (CAMPONEZ, 2012), de meio local (PERUZZO, 2003, 2005), de jornais do interior e de “localismo" (DORNELLES, 2010, 2012).

Para Camponez (2012), o jornalismo de proximidade tem características de prática profissional que conjuga as ideias de espaço geográfico e de temas de interesse de uma coletividade. O tratamento midiático dá voz e espaço aos atores locais, o que faz Camponez (2012) considerar a proximidade como um valor-notícia central do jornalismo, ancorado não apenas na dimensão do território geográfico, mas articulado na combinação dos conceitos de território, lugar, comunicação e comunidade:

(...) jornalismo regional a partir do conceito de pacto comunicacional realizado no contexto de comunidades de lugar - isto é, comunidades que se reconhecem com base em valores e interesses construídos e recriados localmente, a partir de uma vivência territorialmente situada - e onde intervêm critérios como o espaço geográfico de implantação do projeto editorial; o lugar de apreensão, recolha e produção dos acontecimentos noticiados; o espaço privilegiado de difusão da informação; o tipo de conteúdos partilhados e de informação disponibilizada; enfim, a definição dos públicos (CAMPONEZ, 2012, p. 37).

A ideia de proximidade no jornalismo local seria, para o autor, uma “recriação” da identidade e do território, inclusive da profissão e seus públicos.

Na visão de Peruzzo (2005, p. 75), o conceito de proximidade "pode ser explorado a partir de diferentes perspectivas”, ainda que na mídia local e regional se refira "aos laços originados pela familiaridade e pela singularidade de uma determinada região, que têm muito a ver com a questão do locus territorial”.

A questão local será melhor compreendida se apanhada em sua dialeticidade: na existência de elementos de proximidade que se inter-relacionam com o global e o nacional; na confluência e ao mesmo tempo na recusa de demarcações geográficas; na convergência entre identidades e diferenças que 
ajuda a reafirmar ou minar especificidades, porém contribui para gerar novas identidades; na configuração do local e do global como polos, simultaneamente, convergentes e opostos de uma relação (PERUZZO, 2003, p. 69).

Peruzzo (2003, p. 69) utiliza “local” para designar espaços em que “há elos de proximidade e familiaridade, os quais ocorrem por relacionamentos (econômicos, políticos, vizinhança etc.) e laços de identidades os mais diversos”, que não estão demarcados por características geográficas, mas por “conteúdos simbólicos”.

Questões como o espaço geográfico, o lugar de produção e de cobertura dos acontecimentos, o espaço de circulação, os conteúdos locais, a informação disponível, o interesse do público local e a economia das regiões são centrais nos estudos de Dornelles (2010, 2012) sobre jornalismo local. Com base na experiência acumulada em pesquisas sobre os impressos do interior no Rio Grande do Sul, a autora argumentava há uma década que “a bibliografia especializada em 'Jornalismo Interiorano’ (...) é muito pequena e, muitas vezes, equivocada, pois ainda não credita aos jornais do interior a importância que eles de fato possuem para as suas comunidades” (DORNELLES, 2012, p. 22). E que a ausência de estudos faz com que seja "mais fácil encontrar críticas ao jornalismo interiorano do que propostas para contornar problemas que afetam a qualidade do noticiário” (DORNELLES, 2012, p. 22).

O “localismo”, que durante muito tempo não funcionou a favor da imprensa do interior, foi beneficiado pelo jornalismo on-line, que potencializou o interesse por informações locais.

O que podemos observar até o momento, é a utilização cada vez maior da internet pela população em geral como ferramenta de divulgação de informações e, portanto, de notícias. Esta situação favoreceu o localismo, pois ampliou a demanda por informações locais de qualidade. A concorrência por público, de parte da imprensa, está conduzindo os jornais de grandes metrópoles a também ampliarem a divulgação de fatos locais, até então ocupando um espaço periférico na pauta das grandes redações jornalísticas. Fortaleceu-se, assim, a cobertura dos bairros, no que pese ainda ser deficiente, pois continuam prevalecendo os critérios de noticiabilidade, utilizados antes do advento da internet, como raridade, polêmicas, crimes hediondos, economia das elites. E fortaleceu-se, também, o jornalismo popular, que conquistou leitores das classes C e D, conforme divisão econômica do Instituto Brasileiro de Geografia e Estatística (IBGE) (DORNELLES, 2010, p. 238).

A função agregadora da Geografia é percebida por Dornelles (2010) no espaço da mídia local, inclusive nos jornais do interior restritos a regiões, que têm a circulação “irremediavelmente amarrada a questões como o espaço geográfico”. Há, assim, mais de um “papel determinante” que 
(...) a geografia desempenha na definição de informação local. Ela pode ser entendida mais pelo espaço geográfico do que pelas características de seu conteúdo. Já o jornalismo do interior, além da questão geográfica, pode ser reconhecido por outras características próprias por serem do interior. Assim, a comunicação local diz respeito à maioria das pessoas e membros integrados em determinado sistema local, ocorrendo de forma constante. Entende-se por "local” a informação relativa a um bairro urbano ou a uma pequena comunidade ou a cidades de pequeno porte. O próprio jornal local deve ainda refletir a mesma delimitação geográfica, na forma como organiza as informações em cada edição, podendo recorrer mesmo a páginas especiais, destinadas às diferentes situações de cobertura. Ele deve ser constituído por notícias que dizem respeito a uma área geográfica relativamente restrita (DORNELLES, 2010, p. 238).

A mídia local também foi central para a elaboração do conceito de "desertos de notícias” por Penelope (Penny) Abernathy ${ }^{6}$ (2016) em estudos sobre jornais impressos em cidades pequenas desenvolvidos no Centro de Inovação e Sustentabilidade de Mídia Local na Universidade da Carolina do Norte (EUA). Nos Estados Unidos,

(...) os jornais comunitários fornecem até 85\% das "notícias que alimentam a democracia” nos níveis estadual e local. Isso significa que o destino dos jornais e das comunidades está inerentemente vinculado. Se um falhar, o outro sofre. Portanto, importa quem é dono do jornal local porque as decisões tomadas pelos proprietários afetam a saúde e a vitalidade da comunidade (ABERNATHY, 2016, p. 6).

Entre 2015-2016, Abernathy conduziu pesquisas sobre a influência dos conglomerados de mídia no desaparecimento dos pequenos jornais do interior. Na análise da mídia local em vários estados, ela identificou dois movimentos pendulares: de ascensão dos novos "barões da mídia”, os fundos de investimentos privados, e de expansão do que chamou "desertos de notícias"”.

(...) Na última década, um novo barão da mídia surgiu nos Estados Unidos. Fundos de private equity, hedge funds e outras formas de investimento recémcriadas entraram em cena para comprar - e efetivamente administrar - jornais em todo o país. Esses novos proprietários são muito diferentes dos editores de jornais que os precederam. Na maioria das vezes, não têm experiência em jornalismo ou o senso de missão cívica tradicionalmente adotado por editores

6 Ex-executiva do Wall Street Journal e do The New York Times, atualmente chair da Cátedra Knight em Jornalismo e Economia da Mídia Digital na Universidade da Carolina do Norte, em Chapel Hill.

7 The Rise of a New Media Baron and the Emerging Threat of News Deserts. Em: https://www.usnewsdeserts.com/reports/rise-newmedia-baron/executive-summary/. Acesso em 20 jan. 2020. 
e donos de publicações. Os jornais representam apenas uma fração dos vastos portfólios de negócios dessas empresas (ABERNATHY, 2016, p. 7).

O conceito aparece, portanto, vinculado a contextos bem específicos (de negócios, temporal e geográfico) da mídia nos Estados Unidos. No Brasil, a ocorrência dos "desertos de notícias” tem sido explorada pelo Atlas da Notícia, editado pelo Projor - Instituto para o Desenvolvimento do Jornalismo, com dados disponibilizados pelo Volt Data Lab, edições de 2017, 2018, 2019 e 2020. O Atlas é inspirado no projeto America’s Growing News Deserts, da Columbia Journalism Review ${ }^{8}$ e sua meta é mapear veículos que produzem notícias, principalmente locais, em todo o território brasileiro.

Os dados de 2020 do Atlas mostram que existem 3.487 municípios no Brasil (62\%) caracterizados como “desertos de notícias”, representando 27,5 milhões de pessoas, sem qualquer acesso a pelo menos um meio local. Essas pessoas também não estão na agenda da imprensa regional, já que geralmente é estabelecida nas capitais. Depois, vêm os chamados “quase desertos”, locais com um ou dois veículos de comunicação em risco de se transformarem em “desertos de notícias”. Essas localidades representam 19\% dos municípios incluídos na pesquisa Atlas (PROJOR, 2020). As emissoras de rádio (35,2\%), mídia digital (25,5\%), emissoras de TV (9,7\%) e mídia impressa (29,4\%) prevalecem neste ambiente. A versão 2020 do News Atlas não contém nenhuma informação sobre o deslocamento e divulgação de “desertos de notícias” no Brasil; no entanto, dados divulgados em dezembro de 2019 apontaram para as maiores proporções desses “desertos” nas regiões Norte (72\%) e Nordeste (73,5\%).

Na comparação dos “desertos de notícias” no Brasil e nos EUA, notamos duas diferenças e uma semelhança. As diferenças dizem respeito aos meios de comunicação (jornais impressos com maior acesso nos EUA, emissoras de rádio e TV com a maior audiência no Brasil) e ao ambiente de mídia (jornais comunitários nos EUA, emissoras de rádio e TV, principalmente comerciais, no Brasil). A semelhança está na topologia dos desertos: eles estão nas cidades pequenas nos EUA e no Brasil. Entre nós, o desequilíbrio na distribuição de canais convencionais de rádio e TV, balizada por critérios políticos, estimulou a rápida expansão das rádios comunitárias a partir de 2000. Em 2018, mais de 4.500 emissoras de baixa potência estavam em operação (PORTAL BRASILEIRO DE DADOS ABERTOS, 2019).

No caso brasileiro, há evidente correlação entre uma realidade contraditória, marcada por áreas de concentração de mídia e abundância de informação e por áreas de silêncio (desertos?) provocadas pela falta de infraestrutura audiovisual e de telecomunicações em municípios menores e mais distantes dos centros urbanos. Este artigo se propõe a verificar se há mídia local e se ela garante o acesso a informação e conteúdo jornalístico dos moradores das 32 localidades com IDHM Muito Baixo.

8 Disponível em: https://www.cjr.org/local_news/american-news-deserts-donuts-local.php. Acesso em 20 jan. 2020. 


\section{Questões de infraestrutura na produção local}

Considerando a estreita relação entre produção e consumo da informação, os “desertos de notícias” respondem à inexistência de infraestrutura? A análise da produção de mídia nos 32 municípios com IDHM Muito Baixo construiu as referências para o diagnóstico com números, capacidade de alcance e características organizacionais dos meios nesses locais. As informações foram coletadas em bancos de dados públicos, como Anatel, Ministério da Ciência, Tecnologia, Inovações e Comunicações, Atlas do Desenvolvimento Humano no Brasil, Portal Brasileiro de Dados Abertos, Comitê Gestor da Internet e IBGE, completados por levantamento na internet dos meios de comunicação e da administração local nos municípios.

O IDHM brasileiro (PNUD, 2010) considera três dimensões do IDH Global (longevidade, educação e renda) no recorte dos municípios de desenvolvimento Muito Baixo (menor que 0.5 na escala de indicadores). O estudo das localidades permite observar arranjos comunicacionais em partes do território brasileiro acompanhados dos níveis socioeconômicos locais. Assim foram selecionadas como unidades de análise: a) infraestrutura audiovisual canais de rádio, com exceção das emissoras comunitárias, ${ }^{9}$ TV por assinatura, TV aberta e retransmissoras de TV digitais e analógicas; b) telecomunicações - telefonia fixa e móvel, banda larga fixa e móvel e provedores de internet; c) políticas de comunicação para banda larga nos municípios.

Os 32 municípios com pior média de desenvolvimento humano se distribuem entre a região Norte (18) e a região Nordeste (14). As 32 localidades correspondem a 0,57\% dos 5.570 municípios brasileiros e seus 670 mil habitantes representam 0,32\% da população. A renda média per capita está em torno de $\mathrm{R} \$ 158$. Nas demais regiões do país não existem municípios na faixa de IDHM Muito Baixo. O índice Gini ${ }^{10}$, que mede o grau de concentração de renda, mostra que $45 \%$ da população desses municípios são extremamente pobres (DATASUS, 2010).

A observação local sinaliza que a infraestrutura para o setor do audiovisual e das telecomunicações é deficiente nos 32 municípios de IDHM Muito Baixo e, de modo geral, tem

9 O Serviço de Radiodifusão Comunitária foi criado pela Lei 9.612 de 1998 com o objetivo de facilitar a instalação em municípios de rádio de baixa potência (25 Watts) em frequência modulada (FM) com cobertura restrita a um raio de um quilômetro a partir da antena transmissora. Apenas associações e fundações comunitárias sem fins lucrativos com sede na localidade da prestação do serviço podem operar o serviço. Pela lei, as emissoras nessa categoria devem ter uma programação pluralista, estarem abertas à participação dos moradores da região atendida, impedidas de fazer proselitismo político e/ou religioso. A sustentabilidade e a manutenção das emissoras comunitárias dependem da capacidade de mobilização e articulação das associações que exploram a concessão. Essa condição leva as comunitárias a uma dinâmica de permanência irregular no ecossistema midiático e baixa presença na internet, o que dificulta o acesso a informações sobre seu funcionamento. Ao analisar a presença de emissoras comunitárias nos 32 municípios com IDHM muito baixo identificamos que em 12 deles há concessões de canais comunitários na base de dados de serviços interativos da Anatel. Dessas, nenhuma possui website, três possuem streaming disponível em agregadores, e há indícios que metade delas não está em funcionamento. Entre as que estão disponíveis para audição, uma tem programação religiosa (Rádio Afuá FM 87.9, no Pará), outra tem foco em música sertaneja (87.9 FM Santo Antônio do Içá, no Amazonas) e uma terceira transmite música gospel (Rádio Serra 87.9 FM, no Piauí).

$10 \mathrm{O}$ índice Gini se estende de 0 a 1, sendo que 0 representa situação de total igualdade, onde todos têm a mesma renda, e 1 significa profunda desigualdade de renda, ou seja, poucas pessoas detêm toda a renda do lugar (IPEA, 2004). 
sido negligenciada nas regiões mais remotas. O número de emissoras de rádio instaladas é reduzido - a faixa FM está presente em 18\% dos municípios, a faixa AM em 6\%, e inexistem canais de TV com geração própria de conteúdo (Tabela 1). Carentes de mídia local, os municípios são atendidos por retransmissoras de TV analógicas e digitais que reproduzem a programação de emissoras regionais afiliadas a redes nacionais, o que fortalece a política de comunicação da década de 1970 de concentração da produção em poucos conglomerados de mídia. Nessas condições de produção, a circulação e o consumo de conteúdos são regionais ou nacionais; os veículos locais não conseguem garantir a produção de informação sobre as comunidades em que estão inseridos.

Tabela 1 - Quantidade de emissoras de rádio, TV, RTV - Municípios de IDHM Muito Baixo

\begin{tabular}{llll}
\hline Serviços & Emissoras & Municípios & $\mathbf{\%}$ \\
\hline RTV & 45 & 22 & $69 \%$ \\
\hline RTVD (digital) & 23 & 16 & $50 \%$ \\
\hline Rádio FM & 6 & 6 & $18 \%$ \\
\hline Rádio AM & 2 & 2 & $6 \%$ \\
\hline Rádio Ondas Curtas & 0 & 0 & 00 \\
\hline TV & 0 & 0 & 00 \\
\hline
\end{tabular}

Fonte: Tabela elaborada pelos autores com dados do Sistema Mosaico da Anatel, 2021

Dos 32 municípios analisados, nove apresentam baixo fluxo informacional e de comunicação: não têm emissora de rádio, TV ou retransmissora RTV analógica ou digital. Eles estão no Maranhão (Fernando Falcão e Satubinha); no Pará (Cachoeira do Piriá); em Alagoas (Inhapi); e em maior número no Piauí (São Francisco de Assis do Piau, Caxingó, Betânia do Piau, Cocal dos Alves e Assunção do Piauí). Juntos, reúnem 95.309 habitantes (PNUD, 2010) em condições precárias de acesso a meios locais. Os municípios com maior número de serviços de mídia são Santo Antônio do Içá (AM), Itapicuru (BA) e Portel (PA), cada um com seis meios. A Tabela 2 mostra a distribuição das emissoras nas localidades de IDHM Muito Baixo.

Tabela 2 - Distribuição de emissoras de rádio e TV - Municípios com IDHM Muito Baixo

\begin{tabular}{llllll}
\hline Município & FM & AM & RTV & RTVD & TOTAL \\
\hline Santo Antônio do Içá (AM) & 1 & 1 & 3 & 1 & $\mathbf{6}$ \\
\hline Itapicuru (BA) & 1 & 1 & 3 & 1 & $\mathbf{6}$ \\
\hline Portel (PA) & 1 & - & 2 & 3 & $\mathbf{6}$ \\
\hline Afuá (PA) & - & - & 3 & 2 & $\mathbf{5}$ \\
\hline Atalaia do Norte (AM) & 1 & - & 2 & 2 & $\mathbf{5}$ \\
\hline Amajari (RR) & - & - & 3 & 2 & $\mathbf{5}$ \\
\hline
\end{tabular}




\begin{tabular}{|c|c|c|c|c|c|}
\hline Município & FM & $\mathbf{A M}$ & RTV & RTVD & TOTAL \\
\hline Ipixuna do Pará (PA) & 1 & - & 3 & - & 4 \\
\hline Ipixuna (AM) & - & - & 3 & 1 & 4 \\
\hline Santa Isabel do Rio Negro (AM) & - & - & 3 & 1 & 4 \\
\hline Itamarati (AM) & - & - & 3 & 1 & 4 \\
\hline Uiramutã (RR) & - & - & 2 & 1 & 3 \\
\hline Cocal (PI) & - & - & 2 & 1 & 3 \\
\hline Maraã (AM) & - & - & 2 & 1 & 3 \\
\hline Pauini (AM) & - & - & 2 & 1 & 3 \\
\hline Satubinha (MA) & 1 & - & 1 & - & 2 \\
\hline Jordão (AC) & - & - & 1 & 1 & 2 \\
\hline Anajás (PA) & - & - & 1 & 1 & 2 \\
\hline Chaves (PA) & - & - & 2 & - & 2 \\
\hline Melgaço (PA) & - & - & - & 2 & 2 \\
\hline Bagre (PA) & 1 & - & 1 & - & 2 \\
\hline Olivença (AL) & - & - & 1 & - & 1 \\
\hline Manari (PE) & - & - & 1 & - & 1 \\
\hline Marajá do Sena (MA) & - & - & 1 & - & 1 \\
\hline Inhapi (AL) & - & - & - & - & $\mathbf{0}$ \\
\hline Cachoeira do Piriá (PA) & - & - & - & - & $\mathbf{0}$ \\
\hline Jenipapo dos Vieiras (MA) & - & - & - & - & $\mathbf{0}$ \\
\hline Fernando Falcão (MA) & - & - & - & - & $\mathbf{0}$ \\
\hline São Francisco de Assis do Piauí (PI) & - & - & - & - & $\mathbf{0}$ \\
\hline Assunção do Piauí (PI) & - & - & - & - & 0 \\
\hline Cocal dos Alves (PI) & - & - & - & - & $\mathbf{0}$ \\
\hline Betânia do Piauí (PI) & - & - & - & - & $\mathbf{0}$ \\
\hline Caxingó (PI) & - & - & - & - & $\mathbf{0}$ \\
\hline
\end{tabular}

Fonte: Elaborada pelos autores a partir de dados do Sistema Mosaico da Anatel.

A TV por assinatura é um contraponto ao quadro de mídia aberta. Em todos os municípios analisados há domicílios com acesso ao serviço, mas eles atendem, em média, menos de 4\% da população. Algumas diferenças se verificam entre as localidades: em Fernando Falcão (MA) há apenas um assinante de TV por assinatura; Santa Isabel do Rio Negro (AM), Afuá (PA) e Satubinha (MA) têm em média 13 assinantes por 100 domicílios. Players de telefonia dos grupos Claro (Claro Brasil), Telefonica (Vivo TV) e Telemar (Oi TV) conquistam clientes oferendo pacotes com acesso a banda larga e telefonia móvel. Segundo dados da Anatel, a tecnologia de acesso mais utilizada nessas localidades é o DTH (Direct to Home), que exige uma antena externa de satélite, receptor e decodificador para 
recepção. Esse padrão reduz o investimento em infraestrutura pelo provedor, pois os sinais são enviados até o conversor de TV sem intermediários. A Tabela 3 demonstra a densidade ${ }^{11}$ desse serviço nos municípios analisados.

Tabela 3 - Densidade de acesso - TV por assinatura a cada 100 domicílios (2019)

\begin{tabular}{|l|l|l|l|} 
Município & Densidade & Município & Densidade \\
Afuá (PA) & 15 & Cocal dos Alves (PI) & 5,7 \\
Santa Isabel do Rio Negro (AM) & 13 & Chaves (PA) & 5,6 \\
Satubinha (MA) & 12 & Assunção do Piauí (PI) & 5,6 \\
Ipixuna do Pará (PA) & 9,6 & Ipixuna (AM)) & 4,2 \\
Atalaia do Norte (AM) & 8.9 & Olivença (AL) & 4,4 \\
Santo Antônio do Içá (AM) & 8,4 & Pauini (AM) & 4,4 \\
Anajás (PA) & 8,6 & Jenipapo dos Vieiras (MA) & 3,7 \\
Bagre (PA) & 7,7 & Inhapi (AL) & 2,5 \\
Itapicuru (BA) & 7,5 & Amajari (RR) & 1,8 \\
Maraã (AM & 7,3 & Manari (PE) & 1,7 \\
Cocal (PI) & 7,1 & Marajá do Sena (MA) & 1,5 \\
Itamarati (AM) & 6,5 & Jordão (AC) & 0,94 \\
Portel (PA) & 6,3 & São Francisco de Assis do Piauí (PI) & 0,9 \\
Caxingó (PI) & 6,2 & Uiramutã, (RR) & 0,35 \\
Melgaço (PA) & 6.0 & Betânia do Piauí (PI) & 0,3 \\
Cachoeira do Piriá (PA) & 5,9 & Fernando Falcão (MA) & 0.14
\end{tabular}

Fonte: Elaboração dos autores a partir dos Painéis de Dados da Anatel (ANATEL, 2020).

O Serviço Móvel Pessoal (SMP), de telefonia e banda larga móveis, está presente em todos os municípios analisados, onde atuam pelo menos uma operadora que oferece algum tipo de tecnologia para conexão. A média encontrada foi de duas operadoras por município, enquanto em 11 deles apenas uma empresa oferece o serviço. Predominam as tecnologias $2 \mathrm{G}$ e $3 \mathrm{G}$, com menor presença de acesso $4 \mathrm{G}$, o que indica conexão à internet com baixa qualidade.

A banda larga fixa praticamente inexiste: chega a menos de $1 \%$ da população nas 32 localidades estudadas (Tabela 4). Dos 3.665 pontos, a maioria tem velocidade na faixa entre 512kbps e 2Mbps. Em 21 municípios há serviços de conexão de internet com até 34Mbps. As tecnologias utilizadas para acesso a internet incluem rádio e satélite; 22 municípios

11 Densidade de acesso é uma nomenclatura utilizada pela Anatel para designar número de assinantes de serviços como TV por assinatura, telefonia móvel e banda larga por 100 residências no Portal de Dados da Anatel. Disponível em: https://www.anatel.gov.br/ paineis/. Acesso em: 20 jan. 2020. 
usam fibra ótica. A baixa velocidade de banda larga nessas localidades enraíza a situação de exclusão digital e aumenta a desigualdade entre regiões no Brasil.

Tabela 4 - Densidade de acesso a banda larga fixa por 100 domicílios (2019)

\begin{tabular}{llll}
\hline Município & Densidade & Município & Densidade \\
\hline Melgaço (PA) & 12,0 & São Francisco de Assis do Piauí (PI) & 1,1 \\
\hline Pauini (AM) & 8,6 & Inhapi (AL) & 1,0 \\
\hline Anajás (PA) & 6,9 & Chaves (PA) & 0,9 \\
\hline Jenipapo dos Vieiras (MA) & 4,6 & Bagre (PA) & 0,9 \\
\hline Cachoeira do Piriá (PA) & 4,5 & Itamarati (AM) & 0,7 \\
\hline Olivença (AL) & 4,2 & Satubinha (MA) & 0,7 \\
\hline Assunção do Piauí (PI) & 3,0 & Cocal dos Alves (PI) & 0,6 \\
\hline Cocal (PI) & 2,7 & Uiramutã (RR) & 0,6 \\
\hline Afuá (PA) & 2,6 & Portel (PA) & 0,5 \\
\hline Ipixuna (AM) & 1,7 & Fernando Falcão (MA) & 0.4 \\
\hline Ipixuna do Pará (PA) & 1,5 & Atalaia do Norte (AM) & 0.4 \\
\hline Itapicuru (BA) & 1,3 & Marajá do Sena (MA) & 0,4 \\
\hline Amajari (RR) & 1,1 & Jordão (AC) & 0,4 \\
\hline Manari (PE) & 1,2 & Santo Antônio do Içá (AM) & 0,4 \\
\hline Betânia do Piauí (PI) & 1,4 & Santa Isabel do Rio Negro (AM) & 0.3 \\
\hline Caxingó (PI) & 1,1 & Maraã (AM) & 0,3 \\
\hline
\end{tabular}

Fonte: Elaboração dos autores a partir dos Painéis de Dados da Anatel (ANATEL, 2020).

A integração ao Projeto de Telecentros por parte de todos os municípios analisados não alterou a situação (percentual da população atendida por banda larga fixa de boa velocidade) ${ }^{12}$. Cada localidade recebeu oito kits para instalação (servidor, roteador, computadores, impressora e mobiliário); em dez dos 32 municípios analisados houve problemas com o local da instalação: escolas (PORTAL BRASILEIRO DE DADOS ABERTOS, 2019). Na escola, a tendência é que o ponto atenda melhor os alunos, mas reduz o acesso da comunidade. E a entrega do kit pode ocorrer antes que o telecentro esteja instalado ou que a localidade tenha condições técnicas para operá-lo, porque o serviço de acesso público à internet requer gestão local, treinamento de pessoal e suporte técnico.

A primeira camada dos dados verificados mostra que existe uma rede midiática e de serviço de telecomunicações operando com baixo fluxo informacional e de comunicação nos

12 “O projeto de telecentros teve início em 2007, é um Ponto de Inclusão Digital - PID, sem fins lucrativos, de acesso público e gratuito, com computadores conectados à internet, disponíveis para diversos usos. O objetivo do telecentro é promover o desenvolvimento social e econômico das comunidades atendidas, reduzindo a exclusão social e criando oportunidades de inclusão digital aos cidadãos. Os telecentros foram instalados por meio de parcerias entre ministérios, prefeituras e entidades da sociedade civil” (PORTAL BRASILEIRO DADOS ABERTOS, 2019). 
municípios analisados. As retransmissoras de TV em quase todos os municípios indica que a produção da informação está em outro lugar. O conteúdo local reduzido foi confirmado no levantamento do Atlas da Notícia (PROJOR, 2018), que identificou quatro dos 32 municípios de IDHM Muito Baixo analisados neste artigo como “quase desertos” e 27 como “desertos de notícias” (um não fez parte deste levantamento), sem mídia ou produção local e sem cobertura pela imprensa regional.

A observação da infraestrutura, em especial de retransmissoras de TV e emissoras de rádio, revela que nas condições existentes de infraestrutura há espaço para produção de informação local capaz de dinamizar o fluxo informacional centralizado em centros urbanos maiores, geralmente capitais.

\section{Notícias locais em emissoras e retransmissoras}

Uma forma de acesso à informação nos pequenos municípios se dá pela retransmissão dos sinais de estação geradora de televisão, simultânea ou não, com recepção gratuita. Decreto de 2005 regulamentou o serviço assinalando que o objetivo dos canais retransmissores é permitir que os sinais das estações geradoras sejam recebidos em locais onde não chegam os sinais das geradoras ou as condições técnicas são inadequadas. As retransmissoras garantem a formação de redes nacionais e regionais e proíbem a inserção de conteúdo ou publicidade. A única exceção a esta regra está nas localidades em regiões de fronteira e aquelas que integram a Amazônia Legal ${ }^{13}$. Ali, as retransmissoras estão autorizadas a veicular até 15\% de programação local com publicidade. Mesmo assim, a programação deve ter finalidades educativas, artísticas, culturais e informativas, “em benefício do desenvolvimento geral da comunidade” (BRASIL, 2005). 28 dos 32 municípios de IDHM Muito Baixo analisados estão no território da Amazônia Legal.

O sistema de retransmissão RTV na Amazônia Legal foi objeto de pesquisa de campo empreendida pela jornalista Elvira Lobato em três expedições à região em 2017, quando visitou 30 municípios em quatro estados e entrevistou 200 pessoas. Ela observou que os proprietários das retransmissoras são majoritariamente empresários e políticos, embora tenha crescido o número de canais sob controle de grupos religiosos. Na prática, as retransmissoras funcionam como “mini emissoras”, com produção de telejornais locais. Quando esse conteúdo vai ao ar, as emissoras e retransmissoras que estão veiculando conteúdo nacional perdem audiência (LOBATO, 2017, p. 44). Ainda segundo Lobato (2016), os produtores locais têm ensino médio, formados em cursos rápidos de capacitação; muitos recebem das emissoras pouco mais de um salário mínimo e completam sua renda vendendo os anúncios veiculados na programação. A produção de notícias locais pelas RTVs da Amazônia Legal depende da

13 Área na região da floresta amazônica que abrange municípios em nove estados brasileiros. A região é composta por 52 municípios de Rondônia, 22 municípios do Acre, 62 do Amazonas, 15 de Roraima, 144 do Pará, 16 do Amapá, 139 do Tocantins, 141 do Mato Grosso, bem como, por 181 Municípios do Estado do Maranhão (IBGE, 2019). 
capacidade dos seus integrantes de captar publicidade local. O foco não está direcionado ao interesse público.

A adição do Serviço de Retransmissão de Rádio (RTR) para a Amazônia Legal por meio de lei (BRASIL, 2018) é base de infraestrutura que ajuda a viabilizar a produção de conteúdo local. Segundo o MCTIC (2019), existem 131 emissoras de rádio FM com permissão para operar nas nove capitais da Amazônia Legal usando as próprias frequências ou sistemas de estados, municípios, entidades e fundações. Para transmitir o sinal serão expedidas outorgas onerosas aos interessados, que devem participar de edital público lançado pelo MCTIC. As retransmissoras terão $75 \%$ da programação da emissora geradora e apenas $15 \%$ de programação local. Os canais retransmissores de rádio podem veicular publicidade local desde que os blocos de comerciais tenham a mesma duração e se encaixem no horário dos espaços publicitários da estação geradora. A programação local “deverá ter finalidades educativas, artísticas, culturais e informativas, em benefício do desenvolvimento geral da comunidade” (BRASIL, 2018, 2020).

As retransmissoras de rádio na Amazônia Legal viabilizam emissoras em municípios de baixa renda porque a produção de conteúdo é quase sem custo. Mesmo assim, no Plano Básico de Distribuição de Canais da Anatel há 37 canais destinados que estão vagos há anos - três educativos FM, 25 comerciais FM e nove comerciais AM.

As emissoras de rádio instaladas nos municípios analisados indicam que há alguma produção de conteúdo jornalístico local, mas o acesso precário à internet impede o detalhamento da programação das emissoras. Outorgas de oito emissoras de rádio AM e FM foram identificadas no sistema Mosaico da Anatel para os municípios analisados. Três emissoras têm dados da programação em sites, aplicativos e streaming. Quatro emissoras não possuem website e uma tem transmissão web com poucas atualizações e informações sobre a programação (Tabela 5). Na escuta no período de uma semana da programação da Rádio Clube de Itapicuru (Bahia) e do Sistema Arizona de Comunicação (Pará) fica evidente que os noticiários reproduzem o conteúdo de portais de notícias mantidos por grupos de mídia nacionais, com baixo índice de cobertura local. Outro indicativo da precariedade na produção local de informação está no sistema de programação automatizado de transmissão ao vivo de conteúdo geralmente musical.

Tabela 5 - Programação de emissoras de rádio em três municípios com IDHM Muito Baixo

\begin{tabular}{llll}
\hline Emissora & Município & $\begin{array}{l}\text { Grupo/ } \\
\text { Empresa }\end{array}$ & Programação \\
\hline Rádio Clube de Itapicuru & Itapicuru (BA) & $\begin{array}{l}\text { Rádio Clube de } \\
\text { Itapicuru Ltda. }\end{array}$ & Musical, informativa regional \\
\hline Rádio Arucará FM & Portel (PA) & $\begin{array}{l}\text { Sistema Arizona } \\
\text { de Comunicação }\end{array}$ & $\begin{array}{l}\text { Música gospel, religiosa e } \\
\text { informativa com base em } \\
\text { agências de notícias nacionais }\end{array}$ \\
\hline
\end{tabular}




\begin{tabular}{llll}
\hline Emissora & Município & $\begin{array}{l}\text { Grupo/ } \\
\text { Empresa }\end{array}$ & Programação \\
\hline $\begin{array}{l}\text { Rádio Nacional do Alto } \\
\text { Solimões }\end{array}$ & $\begin{array}{l}\text { Atalaia do } \\
\text { Norte (AM) }\end{array}$ & EBC & $\begin{array}{l}\text { A emissora funciona } \\
\text { interligando os nove municípios } \\
\text { da região do Alto Solimões, no }\end{array}$ \\
& & $\begin{array}{l}\text { Amazonas, e serve como fonte } \\
\text { de informação e comunicação }\end{array}$ \\
& & para comunidades e municípios \\
& & da área. O sinal da rádio atinge \\
& & a região da Tríplice Fronteira ${ }^{14}$. \\
& & A programação é musical, \\
& & informativa, educativa, com \\
& & cobertura jornalística no \\
& município de Atalaia do Norte. \\
\hline
\end{tabular}

Fonte: Dados reunidos pelos autores em escuta da programação no site das emissoras (junho-julho 2019).

\section{Algumas conclusões}

Nos modelos de retransmissão de rádio e TV nos municípios analisados há espaços para a inserção de noticiário local. No entanto, é predominante a produção centralizada nas emissoras geradoras localizadas em centros urbanos, dependentes de publicidade local, o que abre portas para acordos com grupos político-econômicos locais, dificultando a pluralidade da informação. Canais de rádio e TV aberta nem sempre operam considerando as diversidades culturais, regionais e midiáticas. $\mathrm{O}$ acesso à internet via celular pode gerar capacidade informativa na região estudada, não necessariamente local. Mudanças na legislação sobre modos de retransmissão de rádio e TV podem representar possibilidades de produção de conteúdos locais e regionais, mesmo que os municípios mais pobres tenham dificuldade em manter uma programação local.

Datado de 1962 e ainda em vigor, o Código Brasileiro de Telecomunicações prevê que emissoras de rádio e de televisão aberta devem garantir 5\% de jornalismo na programação e veicular no máximo 25\% de publicidade do tempo total de programação, entre outras obrigações. Destaca a finalidade educativa-cultural das emissoras, mas o cumprimento dessas atribuições não é monitorado: a fiscalização da Anatel se limita à capacidade técnica de transmissão e o Ministério das Comunicações não tem mecanismos para acompanhar o conteúdo produzido e distribuído. Exemplo da ausência de fiscalização é o arrendamento irregular de parte das grades de programação das emissoras para uso exclusivamente publicitário ou de conteúdo religioso (INTERVOZES, 2012).

14 A Tríplice Fronteira é uma região entre Argentina, Brasil e Paraguai. É a principal fronteira da América do Sul em termos de população, circulação de pessoas e relações internacionais. Para Gimenez et al. (2018), trata-se de uma região internacional em duas dimensões: local e global. 
A observação em campo da infraestrutura para o audiovisual e as telecomunicações nos 32 municípios de IDHM Muito Baixo confirma a falta de políticas norteadas pelo interesse público no lugar de interesses da economia e da política regional e local. O conceito de "desertos de notícias” de Abernathy (2016) e a ideia de localismo de Dornelles (2010) têm parâmetros relevantes para uma definição geral do que seja um noticiário local. As diferenças culturais, econômicas, federativas e educacionais indicam que, no Brasil, um noticiário local com participação do público, da comunidade, na produção ainda é raro. Grandes grupos não têm interesse em cobrir comunidades com poucas pessoas, mesmo que emissoras de rádio locais e de televisão regionais sejam meios de grande alcance e proximidade com o público.

A extensão geográfica do país, as dificuldades para a circulação de bens físicos e o pouco interesse do Estado em estabelecer de fato uma política de comunicação que contemplasse a distribuição equilibrada do espectro radiofônico conteve durante décadas a característica natural das emissoras de rádio e TV como meios locais na sua essência, em torno dos quais as comunidades participassem com produção jornalística própria.

Sem o relacionamento interdependente entre mídia e cidadãos, a expansão de meios locais como o rádio se dá a partir de critérios deliberadamente aleatórios, sem qualquer vínculo com o jornalismo como interesse público. As taxas de analfabetismo de 6,8\% (IBGE, 2019) e de 29\% de analfabetismo funcional (INAF, 2019) ainda são expressivas no Brasil. Não contar com o rádio e a TV aberta com programação local restringe o acesso das pessoas à comunicação e à informação para qualificarem as suas decisões. É preciso organizar a infraestrutura para os meios e ordenar o quadro legal a fim de superar e contornar os processos de “desertificação de notícias” e dar voz às pequenas comunidades do "território usado” de Santos (2007, p. 19).

(...) Todos os mercados, por menores que sejam, são fundamentais - isso também é globalização. Desse modo, por menor que seja um lugar, por mais insignificante que pareça no mundo da competitividade, este lugar é fundamental porque as empresas globais dependem de pequenas contribuições para que possam manter o seu poder. Esse poder é cego, porque não olha ao redor. (...) Mas escolhe lugares aqui e ali, hoje e amanhã, em função das respostas que imaginam poder ter, e desertam esses lugares quando descobrem que já não podem oferecer tais respostas.

Nesta análise, percebemos que o uso do território local, para onde convergem fortes marcas de identidade, indica que comunidades locais podem ressignificar as práticas de reprodução da informação e constituir um campo de interpretação diversa e plural nas várias mídias. 


\section{Referências}

ABERnATHY, P. M. The Rise of a New Media Baron and the Emerging Threat of News media Deserts. The University of North Carolina Press: Center for Innovation and Sustainability in Local Media, 2016.

ABERNATHY, P. M. The Expanding News Desert. The University of North Carolina Press: Center for Innovation and Sustainability in Local Media, 2018.

ANATEL. Painéis de Dados da Anatel. Disponível em: https://www.anatel.gov.br/paineis/. Acesso em: 20 jan. 2020.

ANATEL. Plano de Dados Abertos 2018-2020. Disponível em: https://www.anatel.gov.br/dados/component/ content/article?id=280. Acesso em: 15 maio 2019.

ANATEL. Sistema Moisaco - Canais de radiodifusão. Disponível em: http://sistemas.anatel.gov.br/se/ public/view/b/srd.php. Acesso em: 20 jan. 2020.

ANATEL. Serviços interativos da Anatel. Consulta de estações por localidade. Disponível em: https:// sistemas.anatel.gov.br/easp/Novo/Consulta/Tela.asp?OP=E\&SISQSmodulo=16587. Acesso em: 10 mar. 2021.

ATLAS BRASIL. Atlas do Desenvolvimento Humano no Brasil, 2010. Disponível em: http://www. atlasbrasil.org.br/2013/. Acesso em: 25 maio 2019.

ATLAS BRASIL. Ranking Municipal, 2010b. Disponível em: http://www.atlasbrasil.org.br/2013/pt/ ranking/. Acesso em: 25 maio 2018.

BELTRÃO SPOSITO, M. E. O desafio metodológico de uma abordagem interescalar no estudo de cidades médias. Revista Cidades, v. 3, n. 5, p. 143-157, 2006.

BRASIL. Decreto ${ }^{\circ} 5.371$ de 17/02/2005. Aprova o Regulamento do Serviço de Retransmissão de Televisão e do Serviço de Repetição de Televisão, ancilares ao Serviço de Radiodifusão de Sons e Imagens. Palácio do Planalto. Em: http://www.planalto.gov.br/ccivil_03/_Ato2004-2006/2005/Decreto/D5371.htm. Acesso em: 25 fev. 2019.

BRASIL. Lei $\mathbf{n}^{\mathbf{0}}$ 13.649, de 11/04/2018. Dispõe sobre o Serviço de Retransmissão de Rádio (RTR) na Amazônia Legal. Palácio do Planalto, Casa civil. Disponível em: http://www.planalto.gov.br/ccivil_03/_ Ato2015-2018/2018/Lei/L13649.htm. Acesso em: 6 jun. 2019.

BRASIL. Portal Transparência. Empresa Brasil de Comunicação. Execução orçamentária e financeira 2020. Em: http://www.portaldatransparencia.gov.br/orgaos/20415-empresa-brasil-de-comunicacao-s-a--ebc Acesso em: 11 mar. 2021.

BRASIL, Constituição de 1988, Artigo 221. Disponível em: http://www.planalto.gov.br/ccivil_03/ constituicao/constituicao.htm. Acesso em: 11 mar. 2020.

BRASIL. Decreto $\mathbf{n}^{\mathbf{0}} \mathbf{1 0 . 4 0 5}$, de 25/06/2020. Altera o Regulamento dos Serviços de Radiodifusão. Em: https://www.in.gov.br/web/dou/-/decreto-n-10.405-de-25-de-junho-de-2020-263473205 . Acesso em: 11 fev. 2021.

CAMPONEZ, C. Jornalismo regional: proximidade e distanciações. Linhas de reflexão sobre uma ética da proximidade no jornalismo. In: CORREIA, J. C. (org.). Ágora Jornalismo de Proximidade: Limites, Desafios e Oportunidades. LabCom Books, 2012. Disponível em: http://www.labcom-ifp.ubi.pt/ficheiros/20121224agora_ebook.pdf. Acesso em: 11 fev. 2021.

CENP - Conselho Executivo das Normas Padrão. CENP Meios 2020. Disponível em: https://cenp.com.br/ cenp-meios?id=17 Acesso em: 25 fev. 2021. 
DATASUS. Índice de Gini da renda domiciliar per capita segundo Município 2010. Disponível em: http:// tabnet.datasus.gov.br/cgi/ibge/censo/cnv/ginibr.def. Acesso em: 6 jun. 2019.

DELOITTE. Technology, Media \& Telecommunications. 2020. Disponível em: https://www2.deloitte. com/br/pt/industries/tmtbrasil.html?icid=top_tmtbrasil Acesso em: 14 fev. 2021.

DORNELLES, B. O futuro dos jornais do interior. Intratextos, v. 4, n. 1, p. 21-36, 2012. Disponível em: https:// www.e-publicacoes.uerj.br/index.php/intratextos/article/download/2171/3372 Acesso em: 23 nov. 2020.

DORNELLES, B. O localismo nos jornais do interior. Revista FAMECOS, v. 17, n. 3, p. 237-243, set./ dez. 2010.

FNDC - Frente Nacional pela Democratização da Comunicação. Disponível em: http://fndc.org.br/forum/ quem-somos/. Acesso em: 20 jul. 2019.

GIMENEZ, H. M.; LISBOA, M. T.; SILVA, M. A; DIALLO, M. A. A Tríplice Fronteira como região: Dimensões internacionais. Brazilian Journal of Latin American Studies, v. 17, n. 33, p. 148-167, 2018. Disponível em: https://doi.org/10.11606/issn.1676-6288.prolam.2018.157693. Acesso em: 20 jul. 2019.

HAESBAERT, R. Territórios Alternativos. São Paulo: Contexto, 2009.

IBGE. PNAD Contínua, 2017. Disponível em: https://biblioteca.ibge.gov.br/visualizacao/livros/liv101631_ informativo.pdf. Acesso em: 10 abr. 2019.

IBGE. PNAD Contínua 2018: Educação avança no país, mas desigualdades raciais e por região persistem. Agência de Notícias, 19/06/2019. Disponível em: https://agenciadenoticias.ibge.gov.br/agencia-sala-deimprensa/2013-agencia-de-noticias/releases/24857. Acesso em: 30 jan. 2020.

IBGE. Região de Influência das Cidades, 2020. Disponível em: https://www.ibge.gov.br/geociencias/cartase-mapas/redes-geograficas/15798-regioes-de-influencia-das-cidades.html. Acesso em: 8 mar. 2021.

IBGE. Amazônia Legal. O que é. Mapas regionais, 2019. Disponível em : https://www.ibge.gov.br/geociencias/ cartas-e-mapas/mapas-regionais/15819-amazonia-legal.html?=\&t=o-que-e. Acesso em: 8 mar. 2021.

INAF Brasil 2018. Indicador de Alfabetismo Funcional. São Paulo: agosto de 2018. Disponível em: https:// drive.google.com/file/d/1ez-6jrlrRRUm9JJ3MkwxEUffltjCTEI6/view. Acesso em: 30 jan. 2020.

INTERVOZES. Arrendamento já é irregular e deve ser coibido. 4 jun. 2012. Disponível em: https://intervozes. org.br/arrendamento-ja-e-irregular-e-deve-ser-coibido/. Acesso em: 8 mar. 2021.

IPEA. O que é Índice Gini. 2004. Desafios do desenvolvimento, ano 1, n. 4, 1 nov. 2004. Disponível em https://www.ipea.gov.br/desafios/index.php?option=com_content\&id=2048:catid=28. Acesso em: 7 mar. 2021.

KPMG. Projected Performance 2020-2022. Media and Entertainment sector reports, 2020. Disponível em: https://home.kpmg/in/en/home/insights/2020/09/media-and-entertainment-report-kpmg-india-2020year-off-script/projections-media-and-entertainment-segments.html. Acesso em: 11 fev. 2021.

LOBATO, E. TVs da Amazônia - uma realidade que o Brasil desconhece. APública. Disponível em: https:// apublica.org/tvsdaamazonia/. Acesso em: 1 fev. 2016.

LOBATO, E. Antenas da Floresta: a saga das TVs da Amazônia. Rio de Janeiro: Objetiva, 2017.

MCTIC. Rádios da Amazônia Legal poderão ter retransmissoras. ASCOM, 2019. Disponível em: https:// www.mctic.gov.br/mctic/opencms/salaImprensa/noticias/arquivos/2019/07/Radios_da_Amazonia_Legal_ poderao_ter_retransmissoras.html. Acesso em: 25 jun. 2019.

MEIOS NO BRASIL. Portais de Notícia, 2018. Disponível em: http://www.meiosnobrasil.com.br/?page_ id=572. Acesso em: 10 jun. 2019. 
MOM BRASIL - Monitoramento de Propriedade de Mídia, Brasil. Repórteres Sem Fronteiras/Intervozes, 2017. Disponível em: http://brazil.mom-rsf.org/br/. Acesso em: 15 jul. 2019.

PERUZZO, C, M. K. Mídia regional e local: aspectos conceituais e tendências. Comunicação \& Sociedade, v. 26, n. 43, p. 67-84, 2005.

PERUZZO, C. M. K. Mídia local, uma mídia de proximidade. Comunicação: Veredas, n. 2, p. 65-89, nov. 2003.

PNUD. Atlas do Desenvolvimento Humano no Brasil (Ranking IDH Municipal). Programa das Nações Unidas para o Desenvolvimento. Disponível em: http://www.atlasbrasil.org.br/2013/pt/ rankingAtlasdodesenvolvimentohumano. Acesso em: 25 jan. 2018.

PORTAL BRASILEIRO DE DADOS ABERTOS. Telecentros, SCM, STFC, TV por assinatura e Radiodifusão. Disponível em: https://www.gov.br/anatel/pt-br/dados/dados-abertos. Acesso em: 20 abr. 2019.

PROJOR. Atlas da Notícia - Desertos e quase desertos, uma ocorrência nacional, versão 2.0. Novembro, 2018. Disponível em: https://www.atlas.jor.br/plataforma/estatisticas/. Acesso em: 15 jan. 2020.

PROJOR. Atlas da Notícia - Os desertos de notícias no Brasil. Fevereiro 2020. Disponível em: https:// www.atlas.jor.br/plataforma/estatisticas/. Acesso em: 15 mar. 2021.

PWC Brasil. Estudos Setoriais - Pesquisa Global de Entretenimento e Mídia 2020-2024, 2020. Disponível em: https://www.pwc.com.br/pt/estudos/setores-atividade/outlook-2020/resultados-por-segmentos.html Acesso em: 18 fev. 2021.

SANTOS, M. O dinheiro e o território. In: SANTOS, M.; BECKER, B. Territórios, Território: Ensaios sobre o ordenamento territorial. Rio de Janeiro: Lamparina, 2007.

\section{Sonia Virginia Moreira}

Professora do Programa de Pós-graduação em Comunicação da Universidade do Estado do Rio de Janeiro (UERJ). Bolsista de Produtividade em Pesquisa do CNPq - projeto "Regiões de sombra e de silêncio no Brasil: o setor do audiovisual e das telecomunicações”. Doutora em Ciências da Comunicação pela ECA-USP. Capítulos recentes correlatos ao tema do artigo: Rádios Cipós, experiências analógicas em três cidades pequenas do Maranhão, com Thays A. Reis, em "Rádio no Brasil: 100 anos de história em (re)construção" (Editora Unijuí, 2020); A escassez dos recursos de comunicação em diferentes escalas - A utopia de um país conectado na pandemia de 2020, com Nélia Del Bianco e Jacqueline S. Deolindo, em "Desafios da comunicação em tempos de pandemia - um mundo e muitas vozes” (Editora Intercom, 2020); e Gestão, produção e alcance do jornalismo digital, com Antonia A. Pereira, em "Pedagogia do Jornalismo: desafios, experiências e inovações” (Editora Insular, 2020). E-mail: soniavm@gmail.com.

\section{Nélia Rodrigues Del Bianco}

Professora dos Programas de Pós-Graduação em Comunicação da Universidade de Brasília (UnB) e Universidade Federal de Goiás (UFG). É visitante no Programa de Pós-Graduação em Comunicação da Universidade Federal de Ouro Preto (UFOP). Doutora em Comunicação pela ECA-USP, com estágio de pós-doutorado na Universidade de Sevilha. Obras publicadas como organizadora: 
"Migração do rádio AM para o FM - avaliação de impacto e desafios frente à convergência tecnológica” (Insular, 2018); "80 anos das rádios Nacional e MEC do Rio de Janeiro” (EDIPUCRS, 2017); "O rádio brasileiro na era da convergência” (Intercom, 2012); “Manuel Carlos Chaparro: 70 anos na estrada do texto” (Intercom, 2014). E-mail: nbianco@uol.com.br.

\section{Cézar Franco dos Santos Martins}

Mestrando na linha de pesquisa Mídias e Processos Sociais do Programa de Pós-Graduação em Comunicação (PPGCOM) da Universidade Federal de Juiz de Fora (UFJF). É graduado em Jornalismo pela mesma instituição. Desde 2018, integra o projeto "Estudo sobre regiões de sombra e silêncio no setor audiovisual brasileiro” e é membro do grupo de pesquisa Núcleo de Jornalismo e Audiovisual (NJA). E-mail: cezarfsmartins1997@gmail.com.

Recebido em: 07.02.2020

Aprovado em: 22.03.2021 